\title{
PELATIHAN APLIKASI PERKANTORAN UNTUK MENINGKATKAN KOMPETENSI ANGKATAN KERJA MUDA
}

\section{OFFICE APPLICATION TRAINING TO INCREASE THE COMPETENCE OF THE YOUTH LABOR FORCE}

\author{
Elly Yanuarti", Tri Sugihartono, Sarwindah, Agustina Merdeka Raya \\ Institut Sains dan Bisnis Atma Luhur, Jl. Jend. Sudirman, Kel. Selindung, Kec. Gabek, \\ Pangkalpinang, Provinsi Kepulauan Bangka Belitung \\ *Email: elly@atmaluhur.ac.id
}

(Diterima 20-08-2021; Disetujui 15-09-2021)

\begin{abstract}
ABSTRAK
Jumlah angkatan kerja di Indonesia cukup besar. Angkatan kerja yang tidak memiliki keterampilan akan sulit untuk masuk ke pasar global. Untuk dapat bersaing di pasar global tenaga kerja diharuskan memiliki sertifikasi kompetensi keterampilan tertentu. Kegiatan pengabdian kepada masyarakat berupa pelatihan aplikasi perkantoran ini bertujuan untuk mempersiapkan atau membekali angkatan kerja muda yang akan mengikuti uji kompetensi dan sertifikasi sehingga mampu mendapatkan sertifikat kompeten dalam penguasaan teknologi sebagai operator aplikasi perkantoran. Bahan yang digunakan dalam pelatihan ini adalah perangkat lunak Microsoft office 2016, peralatan pheriperal dan internet. Metode yang digunakan dalam kegiatan pelatihan ini adalah ceramah dan demonstrasi. Materi yang disampaikan berdasarkan Standar Kompetensi Kerja Nasional Indonesia (SKKNI). Berdasarkan penilaian terhadap tugas yang diberikan pada setiap materi yang telah disampaikan dapat terlihat bahwa pengetahuan dan keterampilan para peserta semakin meningkat. Meski ada beberapa kendala yang terjadi saat pelatihan secara keseluruhan kegiatan ini berjalan dengan lancar.
\end{abstract}

Kata kunci: aplikasi perkantoran, kompetensi, sertifikasi, angkatan kerja

\section{ABSTRACT}

The number of labor force in Indonesia is quite large. An unskilled labor force will find it difficult to enter the global market. To be able to compete in the global market, workers are required to have certain skill competency certifications. This community service activity in the form of office application training aims to prepare or equip the young labor force who will take competency and certification tests so that they are able to get a competent certificate in mastering technology as an office application operator. The materials used in this training are Microsoft office 2016 software, peripheral equipment and the internet. The methods used in this training activity are lectures and demonstrations. The material presented is based on the Indonesian National Work Competency Standards (SKKNI). Based on the assessment of the assignments given to each material that has been delivered, it can be seen that the knowledge and skills of the participants are increasing. Although there were several obstacles that occurred during the training, overall this activity went smoothly.

Keywords: office applications, competencies, certifications, labor force

\section{PENDAHULUAN}

Dalam menghadapi revolusi industri 4.0 menjadi tantangan yang sangat besar bagi pemerintah dalam mempersiapkan generasi muda yang memiliki kompetensi kerja agar dapat bersaing di pasar global (Nuraeni, 2019). Industri tentunya lebih mengutamakan untuk memilih tenaga kerja yang lebih berpengalaman dan kompeten di bidangnya.

Jumlah angkatan kerja di Indonesia cukup besar. Angkatan kerja merupakan bagian dari jumlah penduduk yang mempunyai pekerjaan atau yang sedang mencari kesempatan untuk melakukan pekerjaan yang produktif yang disebut sumber daya manusia 
Pelatihan Aplikasi Perkantoran Untuk Meningkatkan Kompetensi Angkatan Kerja Muda

Elly Yanuarti, Tri Sugiarto, Sarwindah, Agustina Merdeka Raya

(Prasetyawati, 2020). Angkatan kerja yang tidak memiliki keterampilan akan sulit untuk masuk ke pasar kerja termasuk juga pekerja yang tidak mau menyesuaikan keterampilan yang mereka miliki dengan perkembangan teknologi berisiko mengalami kehilangan pekerjaan.

Untuk dapat bersaing di pasar global tenaga kerja diharuskan memiliki sertifikasi kompetensi keterampilan tertentu. Sertifikasi kompetensi adalah suatu pengakuan bagi tenaga kerja yang memiliki pengetahuan, keterampilan serta sikap kerja sesuai dengan standar kompetensi kerja yang telah dipersyaratkan (Adam, 2017). Pemerintah melalui Menteri Ketenagakerjaan telah menetapkan Standar Kompetensi Kerja Nasional Indonesia (SKKNI) yang diatur dalam keputusan (Menteri Ketenagakerjaan Republik Indonesia, 2018). SKKNI menjadi dasar dan acuan dalam pendidikan profesi, pelatihan kerja, pengembangan karir di tempat kerja, pengembangan sertifikasi maupun rekognisi kompetensi (Putri, 2018).

Seiring dengan meningkatnya penggunaan teknologi informasi, baik untuk bisnis, pribadi maupun pemerintahan, maka ketersediaan tenaga kerja yang kompeten dalam bidang operator komputer sangat diperlukan. Salah satu upaya pemerintah untuk meningkatkan kualitas atau daya saing SDM adalah menyelenggarakan sertifikasi kompetensi berbasis SKKNI bidang pengoperasian komputer. Berdasarkan hal tersebut, untuk mendukung kelancaran kegiatan sertifikasi tersebut diadakan kegiatan pelatihan penggunaan aplikasi perkantoran.

Secara umum tujuan dari kegiatan pelatihan ini antara lain:

1. Mengurangi pengangguran.

2. Meningkatkan dan alih kompetensi .

3. Meningkatkan daya saing dalam penguasaan teknologi.

Secara khusus kegiatan pelatihan ini adalah mempersiapkan atau membekali angkatan kerja muda yang akan mengikuti uji kompetensi dan sertifikasi sehingga mampu mendapatkan sertifikat kompeten dalam penguasaan teknologi sebagai operator komputer sehingga dapat bersaing di dunia kerja.

Pada dasarnya pelatihan peningkatan kompetensi tentang penggunaan aplikasi perkantoran sudah banyak dilakukan beberapa, diantaranya adalah seperti pelatihan yang dilakukan oleh (Solihin et al., 2020) bagi karang taruna guna meningkatkan keterampilan administrasi. Ada juga pelatihan bagi personel Polri Tegal Kota yang dilakukan oleh (Afriliana et al., 2021). Selain itu, ada juga pelatihan bagi staf Kecamatan Talang guna peningkatan pelayanan administratif (Afriliana et al., 2020), serta pelatihan bagi warga dan 
perangkat desa Karangduren yang dilakukan oleh (Ariyanto et al., 2020).

Dari berbagai kegiatan pengabdian kepada masyarakat yang disebutkan di atas semuanya mengarah pada peningkatan kompetensi dalam menjalankan kegiatan administrasi sehari-hari. Adapun yang berbeda dari kegiatan pengabdian kepada masyarakat ini adalah mengenai materi yang disampaikan. Materi dalam pelatihan peningkatan kompetensi ini berbasis SKKNI.

\section{BAHAN DAN METODE}

Kegiatan pengabdian masyarakat ini dilaksanakan di Hotel Fox Harris selama 3 hari yang dimulai pada tanggal 9 sampai 11 November 2020. Sasaran dari kegiatan pelatihan ini adalah peserta umum yang merupakan angkatan kerja muda lulusan SMK/SMA/D1/D2/D3/D4 sederajat yang memiliki pengetahuan tentang aplikasi perkantoran, baik yang belum mendapatkan pekerjaan tetap maupun pernah bekerja, tetapi sedang tidak bekerja. Adapun jumlahnya sebanyak 20 peserta.

Kegiatan pengabdian kepada masyarakat ini dilaksanakan dalam beberapa tahapan, yaitu:

Tahap 1

Pada tahap ini para peserta mendaftar secara online.

Tahap 2

Pada tahap ini para peserta diberikan paparan tentang rencana pengembangan SDM TIK dalam menghadapi Revolusi Industri 4.0.

Tahap 3

Pada tahap ini peserta diberikan materi untuk penyegaran kembali sesuai topik yang akan diuji dan mempraktikkannya.

Metode yang digunakan dalam kegiatan pengabdian masyarakat ini adalah ceramah dan demonstrasi. Terlebih dahulu dilakukan penyampaian materi menggunakan LCD proyektor kepada peserta. Selanjutnya, sambil pemateri mendemonstrasikan materi peserta mempraktekkan secara langsung sambil melihat materi yang sedang dibahas sesuai dengan instruksi dari pemateri. Pada setiap akhir pembahasan peserta diberi tugas untuk dilakukan penilaian terhadap sejauh mana pemahaman peserta terhadap materi yang sudah disampaikan.

Spesifikasi alat dan bahan yang dibutuhkan dalam kegiatan pelatihan ini adalah:

1. Laptop

2. LCD Proyektor 
3. Internet

4. Printer

5. Aplikasi Microsoft Office 2016

\section{HASIL DAN PEMBAHASAN}

Kegiatan pengabdian masyarakat yang dilaksanakan pada bulan November 2020 ini dilaksanakan selama 3 hari. Jumlah materi yang disampaikan kepada peserta sebanyak 9 materi dimana setiap harinya disampaikan 3 materi yang berbeda. Pada hari pertama yaitu Senin, 9 November 2020 peserta diberi materi seperti terlihat pada Tabel 1.

Tabel 1. Materi Hari Ke-1

\begin{tabular}{cll}
\hline Sesi & \multicolumn{1}{c}{ Nama Materi } & Waktu \\
\hline 1. & Menggunakan Perangkat lunak pengolah kata (Ms. Word) & 3 jam \\
2. & Menggunakan Aplikasi Berbasis Internet & 3 jam \\
3. & Menggunakan Aplikasi Media Sosial & 2 jam \\
\hline
\end{tabular}

Pada sesi 1 materi yang disampaikan adalah tentang penggunaan perangkat lunak pengolah kata selama 3 jam. Sebenarnya untuk pengolah kata ini semua peserta sudah tidak asing lagi karena sudah pernah mengoperasikannya sehingga tidak ada kesulitan dalam mempraktikkannya. Pada sesi ini peserta juga diberi tips dan trik dalam menggunakan pengolah kata agar lebih mudah dan cepat dalam mengoperasikannya. Materi yang disampaikan tentang pengolah kata ini adalah materi dasar, antara lain cara membuat dokumen, mengatur dan menyesuaikan tata letak dokumen, membuat tabel, menambah gambar dan mencetak dokumen. Pada sesi 2 materi yang disampaikan tentang bagaimana menggunakan aplikasi berbasis internet yang antara lain cara mengkoneksikan internet, macam aplikasi berbasis internet dan cara menjalankannya. Pada sesi 3 selama 2 jam terakhir peserta diberikan materi tentang cara menggunakan aplikasi media sosial seperti cara memilih media sosial sesuai kebutuhan, mengelola akun di media sosial dan mengirimkan informasi di media sosial. Situasi kegiatan penyampaian materi pada hari pertama seperti terlihat pada Gambar 1. 


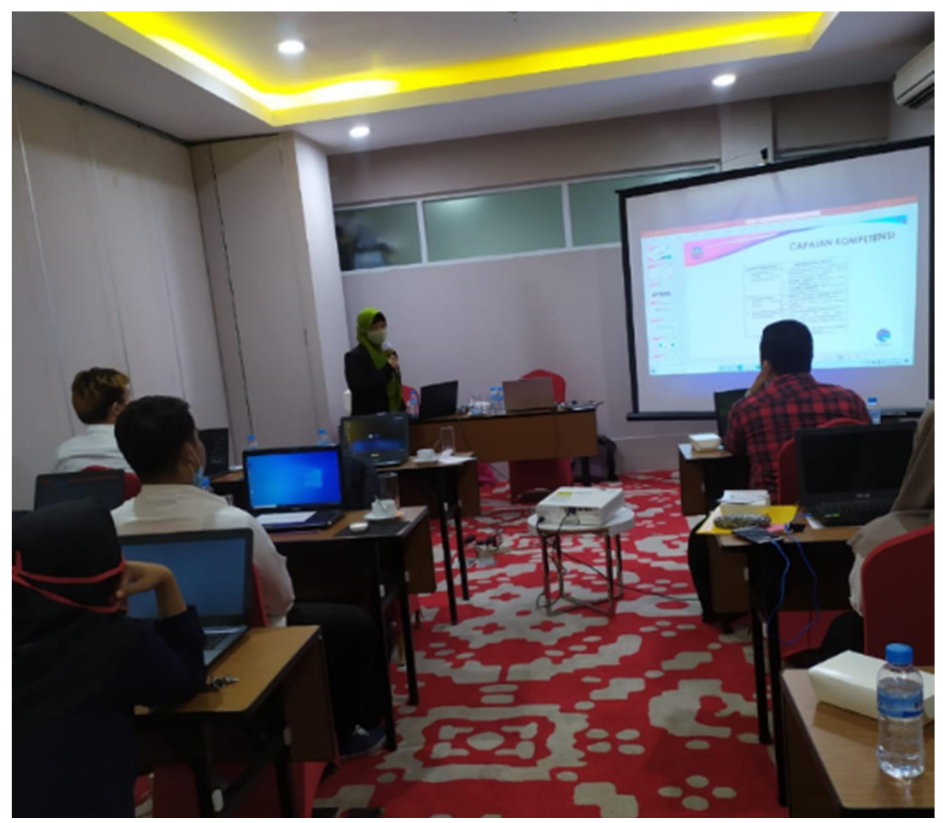

Gambar 1. Penyampaian Materi Hari Ke-1

Gambar 2 memperlihatkan situasi pada saat peserta mempraktikkan latihan soal yang diberikan oleh pemateri. Peserta sangat antusias dalam mengerjakannya.

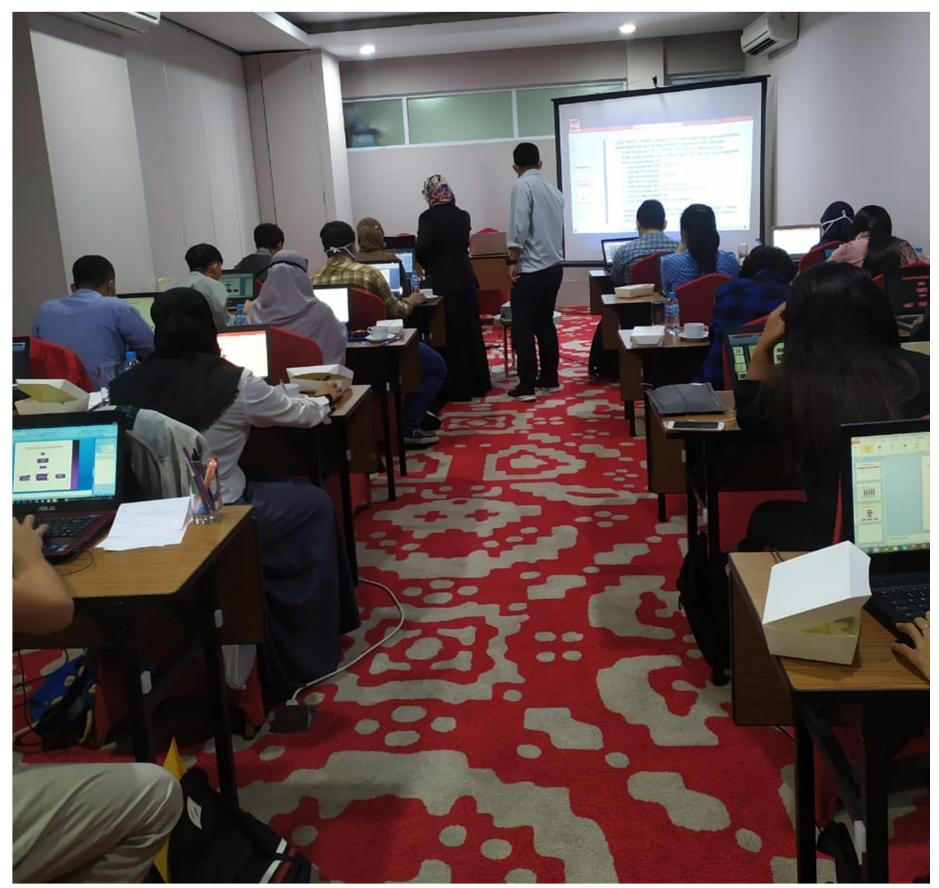

Gambar 2. Kegiatan Praktik Peserta Hari Ke-1

Pada hari kedua yaitu Selasa tanggal 10 November 2020, peserta dibekali materi seperti yang terlihat pada Tabel 2. 
Pelatihan Aplikasi Perkantoran Untuk Meningkatkan Kompetensi Angkatan Kerja Muda

Elly Yanuarti, Tri Sugiarto, Sarwindah, Agustina Merdeka Raya

Tabel 2. Materi Hari Ke-2

\begin{tabular}{cll}
\hline No & \multicolumn{1}{c}{ Nama Materi } & Waktu \\
\hline 1. & Menggunakan Perangkat lunak presentasi (Ms. Powerpoint) & 3 jam \\
2. & Menggunakan Perangkat lunak spreadsheet (Ms. Excel) & 3 jam \\
3. & Menggunakan Peralatan Pheriperal & 2 jam \\
\hline
\end{tabular}

Pada hari kedua ini, pada sesi 1 peserta diberikan materi tentang cara menggunakan perangkat lunak presentasi tingkat dasar seperti bagaimana mempersiapkan aplikasi, membuat file presentasi, melakukan editing sederhana, menggunakan template presentasi, menggunakan gambar, menjalankan presentasi serta mencetak file presentasi. Pada sesi 2 peserta diberikan materi tentang cara menggunakan perangkat lunak spreedsheet tingkat dasar seperti membuat dokumen spreedsheet, melakukan editing dan mencetak dokumen. Sedangkan pada sesi terakhir peserta diberikan materi cara menggunakan peralatan pheriperal seperti memastikan koneksi peralatan pheriperal, menggunakan printer dan scaner serta setting peralatan dan mematikan peralatan. Adapun situasi kegiatan pada hari kedua saat penyampaian materi tampak seperti Gambar 3.

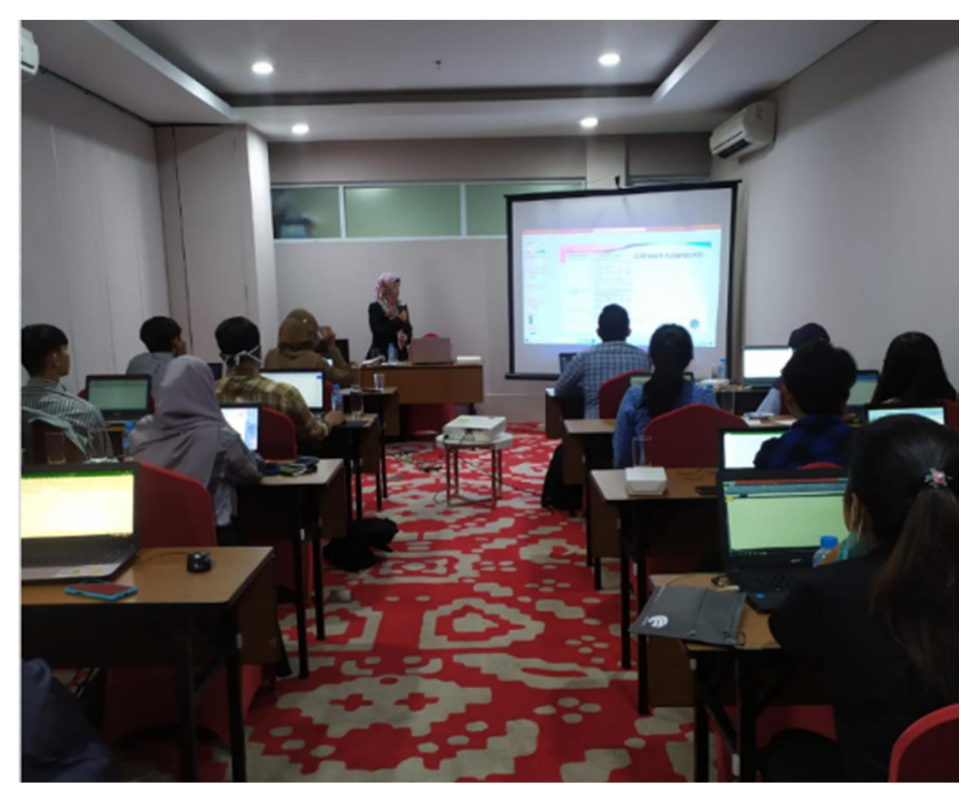

Gambar 3. Penyampaian Materi Hari Ke-2

Pada Gambar 4 terlihat peserta fokus dalam mengerjakan latihan yang diberikan oleh pemateri. 


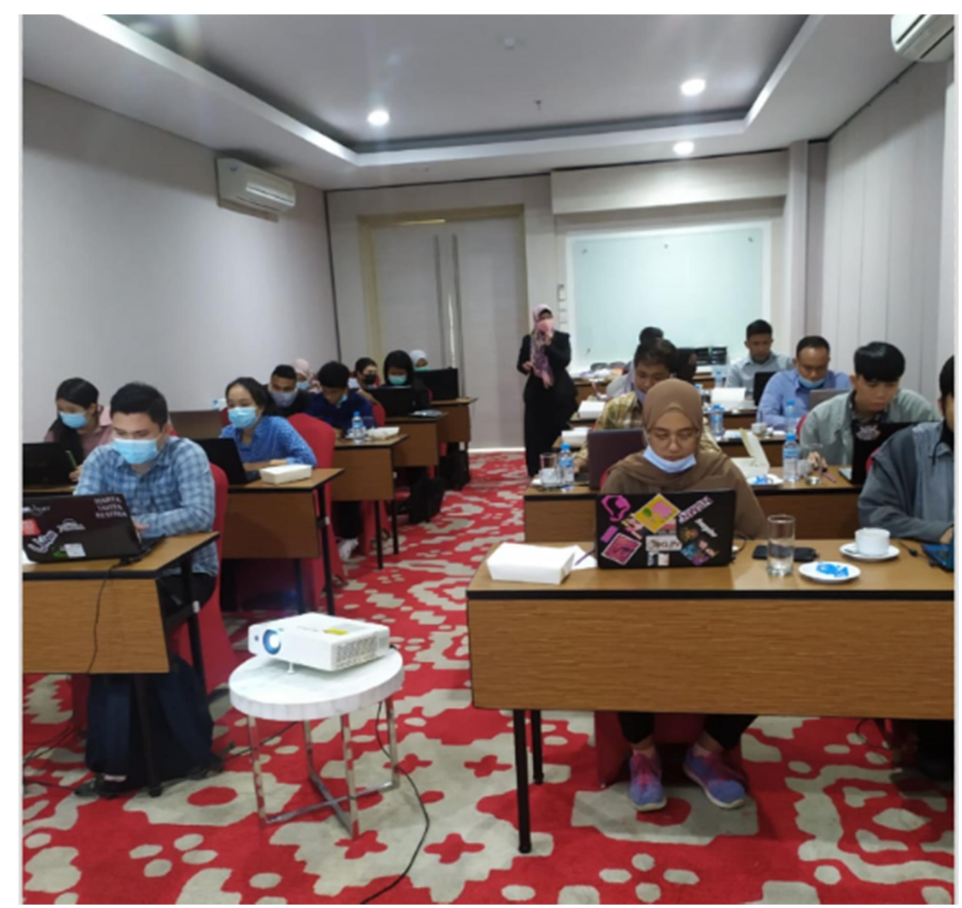

Gambar 4. Kegiatan Praktik Peserta Hari Ke-2

Pada hari ketiga yaitu Rabu tanggal 11 November 2020, peserta dibekali materi seperti yang terlihat pada Tabel 3 .

Tabel 3. Materi Hari Ke-3

\begin{tabular}{lll}
\hline No & \multicolumn{1}{c}{ Nama Materi } & Waktu \\
\hline 1. & Menggunakan Perangkat lunak Pengakses Surat Elektronik (E-mail Client) & 3 jam \\
2. & Validitas Data & 3 jam \\
3. & Megidentifikasi Aspek Keamanan Informasi Pengguna & 2 jam \\
\hline
\end{tabular}

Pada hari ketiga ini pada sesi 1 peserta diberikan materi tentang cara menggunakan perangkat lunak pengakses surat elektronik (e-mail client) antara lain cara mempersiapkan perangkat lunak, membaca dan membuat surat elektronik, dan mengorganikasikan surat elektronik. Pada sesi 2 materi yang diberikan tentang validitas data seperti identifikasi substansi dan referensi data yang dimasukkan, memeriksa validitas data dan melakukan pemutakhiran data. Adapun situasi kegiatan pada hari kedua tampak seperti Gambar 5 dan 6. 


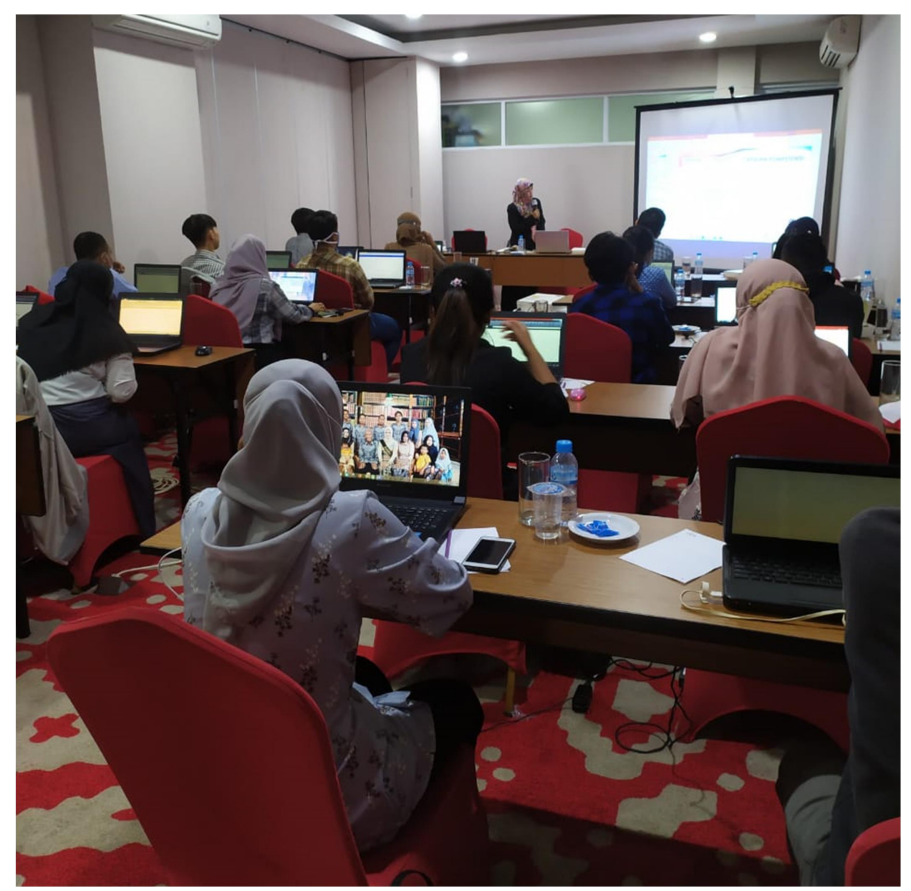

Gambar 5. Penyampaian Materi Hari Ke-3

Pada gambar ke 6 tampak pemateri membantu menjelaskan ke peserta yang kurang paham dan bingung saat mempraktikkan materi.

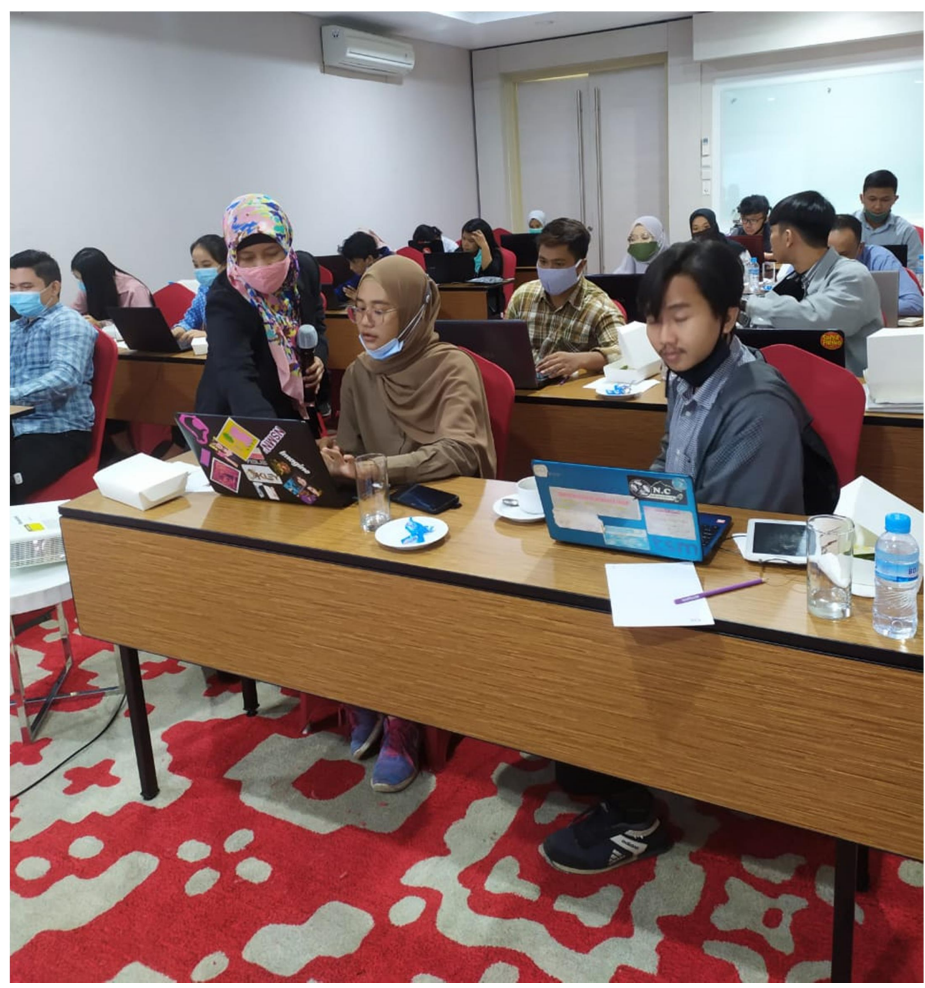

Gambar 6. Kegiatan Praktik Peserta Hari Ke-3 
Selama kegiatan berlangsung para peserta tampak semangat menyimak materi yang disampaikan dan fokus mengerjakan latihan yang diberikan oleh pemateri. Para peserta aktif bertanya jika ada materi yang dirasa kurang paham serta semangat dan fokus mengerjakan latihan dan mengikuti instruksi yang diberikan oleh pemateri. Pada setiap sesi, di akhir pembahasan materi peserta diberikan tugas dengan tujuan untuk menilai dan melihat sejauh mana pemahaman peserta terhadap materi yang telah diberikan.

Selama 3 hari kegiatan berlangsung yang menjadi kendalanya adalah jaringan internet dan spesifikasi laptop peserta yang tidak support. Ada laptop peserta yang mengalami kendala hang dan versi aplikasi yang belum sesuai dengan kebutuhan. Namun, secara keseluruhan kegiatan pengabdian kepada masyarakat ini berjalan dengan lancar.

\section{KESIMPULAN DAN SARAN}

Kegiatan pelatihan aplikasi perkantoran ini diikuti oleh peserta yang akan mengikuti uji kompetensi dan sertifikasi berbasis SKKNI. Peserta terlihat antusias dan semangat mengikuti pelatihan ini karena peserta dibekali dengan materi yang sesuai dengan materi yang akan diujikan. Kegiatan pelatihan ini merupakan kegiatan untuk mempersiapkan peserta agar mampu mengikuti uji kompetensi dan sertifikasi sehingga dapat menjadi operator komputer yang kompeten.

\section{UCAPAN TERIMA KASIH}

Tim pengabdian kepada masyarakat mengucapkan terima kasih kepada Rektor Institut Sains dan Bisnis Atma Luhur dan Ketua LPPM Institut Sains dan Bisnis Atma Luhur atas dukungannya dan juga karena telah mendanai kegiatan pengabdian kepada masyarakat ini sehingga kegiatan pengabdian kepada masyarakat ini dapat berjalan dengan lancar. Tidak lupa juga kami ucapkan terima kasih kepada pihak-pihak yang sudah membantu terlaksananya kegiatan pengabdian kepada masyarakat ini.

\section{DAFTAR PUSTAKA}

Adam, L. (2017). Membangun Daya Saing Tenaga Kerja Indonesia Melalui Peningkatan Produktivitas. Jurnal Kependudukan Indonesia, 11(2), 71. https://doi.org/10.14203/jki.v11i2.205

Afriliana, I., Budihartono, E., \& Rais. (2021). Peningkatan Ketrampilan dan Kemampuan Komputer Melalui Pelatihan Aplikasi Perkantoran Bagi Personel Polri Tegal Kota. JMM (Jurnal Masyarakat Mandiri ), 5(4), 1790-1797.

Afriliana, I., Rakhman, A., Nurohim, \& Maulana, A. (2020). Peningkatan Pelayanan Administratif Bagi Staf Kecamatan Talang Melalui Penguatan Kompetensi Aplikasi 
Perkantoran. Darmabakti: Jurnal Pengabdian Dan Pemberdayaan Masyarakat, 1(1), 1-5. https://doi.org/10.31102/darmabakti.2020.1.1.1-5

Ariyanto, Y., Nurul Asri, A., Puspitasari, D., Astiningrum, M., \& Yunhasnawa, Y. (2020). Pelatihan Administrasi Perkantoran Microsoft Office Untuk Warga dan Perangkat Desa Karangduren, Kec. Pakisaji, Kab. Malang. Jurnal Pengabdian Polinema Kepada Masyarakat, 7(2), 222-226.

Keputusan Menteri Ketenagakerjaan Republik Indonesia Nomor 56 Tahun 2018 Tentang Penetapan Standar Kompetensi dan Komunikasi Golongan Pokok Aktivitas Jasa Informasi Bidang Pengoperasian Komputer, 1 (2018).

Nuraeni, Y. (2019). Tantangan Dan Peluang Implementasi Skills Development Fund (Sdf) Di Indonesia Dalama Rangka Peningkatan Kompetensi Tenaga .... Seminar Nasional Sistem Informasi (SENASIF), September. https://www.jurnalfti.unmer.ac.id/index.php/senasif/article/view/251

Prasetyawati, S. E. (2020). Pengaturan Kepemilikan Sertifikasi Kompetensi Bagi Tenaga Kerja Profesional (Studi pada PT. Keandra Jaya Sakti Kota Bandar Lampung). Jurnal Keadilan Progresif, Vol. 11(1), 49-61.

Putri, S. Y. (2018). Upaya Pemerintah Indonesia di Era Pemerintahan Presiden Joko WIdodo dalam Meningkatkan Daya Saing Sektor Ketenagakerjaan. Jurnal Kajian Lemhannas RI, 19(3), 19-33.

Solihin, L., Suminto, Setiawan, A., \& Juhana. (2020). Pelatihan Peningkatan Kompetensi Menggunakan Aplikasi Perkantoran Pada Karang Taruna RT 05 RW 08 Desa Gelam Jaya Kec. Pasar Kemis Kab. Tangerang. Prosiding Senantias, 1(1), 651-660. 